\title{
The 3\% Problem:
}

\section{Why Are There So Few Females in Creative Advertising?}

\author{
Aleeza Yermus \\ Masters Research Paper \\ Supervised by: Dr. Matthew Tiessen \\ Second reader: Dr. Robert Clapperton
}

July 25, 2017

Ryerson University

Master of Professional Communication

Faculty of Communication and Design 


\begin{abstract}
The purpose of this Masters Research Paper is to examine the role of women in the creative advertising industry. After extensive research into this area of study, it is evident that globally, women make up a very small percentage of the creative roles and executive positions within the advertising industry (Jean Grow \& Tao Deng, 2014). Given this state of affairs, consciousness-raising movements like The 3\% Conference, for example, (Jesse Thomas, 2012) have emerged in order to raise awareness of this problem and to promote change for women in the advertising industry in the United States and beyond.
\end{abstract}

The literature review that informs the original research conducted in this MRP will analyze the historical trends of women in the creative departments of the global advertising industry in practice and in popular culture and some of the factors that may contribute to this gender disparity - the objective was to examine and gain an understanding of why this gender gap persists. The data was then collected from three different media sources: the television show Mad Men, the documentary film Art \& Copy and an online movement called The 3\% Conference. My findings were derived from a series of content analyses that enabled me to determine how the media and online professional organizations like The 3\% Conference portray women in creative advertising in North America. Lastly, the literature review was compared to the results from the data, to determine whether the media offers a reliable depiction of women in the creative advertising industry. 


\section{TABLE OF CONTENTS}

1. Introduction........................................................... 1

2. Research Questions....................................................... 3

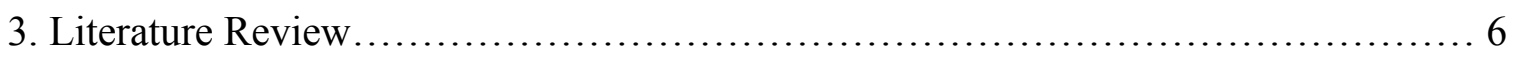

2.1 A Historical Trajectory of Women in Creative Advertising in Practice and Pop

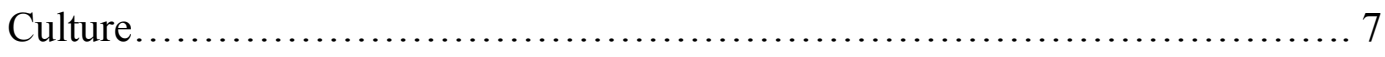

2.2 Internal and External Factors Contributing to Gender Disparity.............11

2.3 Overcoming Barriers and the Gender Divide......................... 17

4. Data Collection and Methods............................................ 20

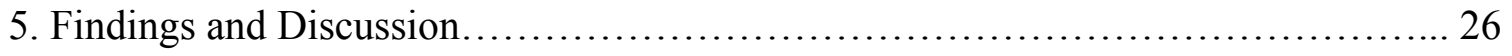

5.1 Visual Content Analysis...........................................26

5.2 Textual Content Analysis......................................... 34

6. Limitations and Future Research.......................................... 39

7. Conclusion......................................................... 42

References............................................................... 45

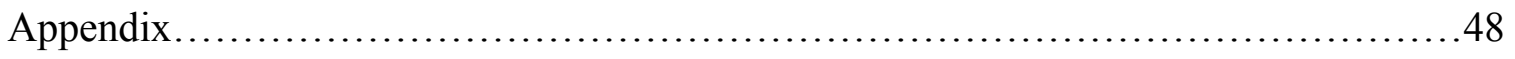




\section{1) INTRODUCTION}

The purpose of this Masters Research Paper is to examine the role of women in the creative advertising industry. The standard creative departments at most advertising agencies around the world are made up of art directors, copywriters, designers, and creative directors (Grow \& Broyles, 2011). Globally, women make up a very small percentage of the creative roles within the advertising industry (Jean Grow \& Tao Deng, 2014). I am especially interested in this topic since it relates to me on a personal level due to my being a woman eager to pursue a career in the creative advertising sector, specifically, as an art director. I recently interned at an advertising agency in Toronto as an art director, where I gained hands-on experience and exposure to this field. In my experience working at this agency, as well as speaking to a few creative directors at different firms around Toronto, I found that a shocking majority of the people in creative positions were men - I became eager to learn why. I gained further insight to this topic after attending a talk at Miami Ad School which discussed The 3\% Conference (Jesse Thomas, 2012), a movement created in 2008 to raise awareness of this problem and to promote change for women in the advertising industry worldwide. The movement's title, The 3\% Conference, reflects the shockingly low percentage (3 percent) of females in creative advertising across the United States; since the conference began, this number has risen from three to eleven percent.

To explore the role of women in the creative advertising industry, this MRP will be divided into seven sections: 1) introduction; 2) literature review; 3) research questions;

4) data collection and methods; 5) findings and discussion; 6) limitations and future 
research; and 7) conclusion. I am fascinated by this subject and hope to gain more knowledge about why this gender gap persists and what positive changes can be made within the advertising industry to close this gap. 


\section{2) RESEARCH QUESTIONS}

This MRP will focus on the following three research questions:

- Research Question 1: Why have women historically made up such a small percentage of creative roles in the advertising industry globally and which factors may contribute to this development?

- Research Question 2: How do different media platforms (film, television and online movements) portray women in creative advertising in North America?

- Research Question 3: Does the portrayal of women in creative advertising in popular culture offer a reliable depiction of the historical nature of women's roles, as discussed in the literature?

To address the first research question, this paper will draw upon past literature to determine which factors (both internal and external) may contribute to gender disparity in the advertising industry globally, in an attempt to understand why this gender gap persists. In terms of past literature, Mallia (2009), Windels and Lee (2012) and Grow \& Deng (2014) offer a variety of reasons for this gender gap and present a range of factors that may contribute to this disparity, including: occupational stereotypes, creative advertising fostering a boys' club mentality, a lack of visibility of women at the top, the ways the industry is not responsive to the needs of employees (particularly women) to raise a family, and several more sociological, cultural and psychological factors.

Arnberg and Syanlund (2016), Grow (2008) and Windels and Lee (2012) offer insight into the second research question and explain some of the ways the media 
portrays women in advertising. While these sources primarily discuss the television series Mad Men and how the show depicts women in the advertising industry, this MRP will discuss two other areas of the media as well (the documentary film Art \& Copy and The 3\% Conference), to gain insight into the ways the portrayal of women in popular culture has had an impact on the ability for women to enter and rise up within the industry. The inclusion of a documentary film (Art \& Copy), a television series (Mad Men) and an online platform (The 3\% Conference), offers a variety of different lenses to use to gain some perspective on these issues and will help us gain insight into the first research question as well.

For the third research question, this MRP will assess whether these media forms accurately depict the roles of women in advertising in real life, from the early 1950s until today. By collecting data in this study (through a content analysis of Art \& Copy documentary, Mad Men and The 3\% Conference and a critical analysis of the literature) this paper will make comparisons between how the media portrays women in advertising and whether or not this aligns with their roles in real life. By drawing upon how different media sources depict women in creative advertising and relating these findings to women's roles in practice (as documented in the literature), this MRP will seek to gain insight into how the media influences the thoughts and actions of women in this industry. Specifically, this comparison may shed light on why certain women are able to overcome barriers in the advertising industry and surpass this gender divide, whereas others cannot. This MRP will draw especially upon the works of Broyles and Grow (2011) and Mallia (2009) to assess the factors that differentiate women who persevered in 
creative advertising, versus those were phased out of the industry, such as family life, adaptation to organizational politics, and more aggressive male personalities. 


\section{3) LITERATURE REVIEW}

The literature review will analyze three different areas. Firstly, I will focus on the literature that explains historical trends of women in the creative departments of the global advertising industry in practice and in popular culture. The authors Arnberg and Syanlund (2016) and Grow (2008) offer insight into this area of research, delving into how the media portrays women in advertising and whether these depictions accurately capture their roles in this industry. Secondly, this review will draw upon established theories and past literature to determine which factors (both internal and external) may contribute to this gender disparity in the advertising industry. My objective was to attempt to understand why this gender gap persists. In terms of previous research, Mats Alvesson (1998) and Grow \& Broyles (2011) offer a variety of reasons for this gender gap. Finally, this literature review will examine how women in creative advertising may overcome these barriers and thrive in creative departments. Drawing upon the works of Broyles and Grow (2011) and Mallia (2009), this paper will analyze which elements differentiate women who persevered in the industry versus those who were phased out and offer advice to future female creatives.

While there is an ample amount of research that observes the advertising industry as a whole, there is limited literature that discusses the gender disparities within creative advertising departments specifically. Few researchers have analyzed the longstanding gender gap that exists within the creative departments of advertising agencies around the globe. In recent years, however, this topic has gained greater recognition and attention (Grow, Roca, \& Broyles, 2012). The research that does exist on this topic often takes the 
form of small-scale case studies that only look at one country, such as Alvesson's (1998) ethnographic study in Sweden, or cross-cultural analyses looking at two countries, such as Grow et al. (2012) comparing Spain and the US, or Grow and Broyles (2008) comparison of the US and Canada. While this research offers insight into the advertising industry in specific geographic locations, it is limited in scope and only targets one or two countries at a time. For this reason, the literature review of this MRP will look at creative departments within the advertising industry on a more global scale, in order to observe this issue as a worldwide phenomenon and to attempt to develop solutions that could bring about positive change. In this sense, my MRP will resemble more of a crossnational study, similar to Grow and Deng (2014) or Mallia (2009), while encompassing a unique methodological approach.

\section{$\underline{2.1 \text { A Historical Trajectory of Women in Creative Advertising in Practice and Pop }}$}

\section{Culture}

A vast amount of the existing research in this area of study, such as Grow and Broyles (2008) and Grow et al. (2012), discusses the historical role of women in the advertising industry in real life as well as how females working in creative advertising have been depicted in popular culture. Firstly, in terms of the portrayal of women in popular culture, much of the literature points to the television series Mad Men (2007-15) that follows the life of a fictional creative director, Donald Draper, who runs a primarily male-dominated, prestigious advertising agency in New York City called Sterling Cooper. The show successfully presents the American advertising industry as a "man's 
world" (Grow et al., 2012, p. 659) or a boys' club (Grow \& Broyles, 2008), projecting an image of men at the top in the advertising industry and males holding the majority of creative and respected managerial positions. The title of the show Mad Man in itself focuses specifically on men, blatantly alluding to the dominance of males in advertising agencies in America (Grow et al., 2012). Consequently, while the admen's wives in the show play the role of 1960s housewives, the majority of women at the agency take on secretarial, administrative or subordinate positions in the office. Few female characters were able to transcend their stereotypical roles in the show and those that did were often still unable to achieve equal status as men (Windels \& Lee, 2012). Much of the research on Mad Men explains how the series illustrates the challenges that women face in the advertising industry, how women often don't rise up to leading positions, and the ways that females are excluded from creative campaigns (Phelps, 2014). The literature discussed above merely scratches the surface in regards to how popular culture represents women in the advertising industry. While there is a considerable amount of research discussing the portrayal of women in specific advertisements and in the media, there is far less that observes how popular culture displays women's positions in the advertising world. For this reason, in this MRP I will delve into this topic more deeply, explore the show Mad Men in more depth (as it is the series' $10^{\text {th }}$ anniversary), and will look into other popular culture examples including a documentary film and a contemporary online movement.

Much of the literature in this area also discusses the historical position of women in creative departments of advertising agencies in real-life practice; several themes emerge in this research. While the popular culture discussion mentioned above mainly 
focuses on the American advertising industry, the following section will discuss the research about the industry on a global scale. A common theme that emerges in the literature is that while men in the advertising industry have not outnumbered women over time, females still make up a smaller percentage of creative roles and managerial positions than men (Grow \& Broyles, 2008). Due to the overwhelming dominance of men in creative departments, this may have far greater consequences in this department specifically, compared to others, such as the accounts sector (Gregory, 2009). An example of this gender disparity in creative advertising departments is depicted through an ethnographic case study which was conducted using participant observation of 21 individuals in the Swedish advertising industry, where the findings indicated that men and women are clearly divided in the agency, and that men hold all creative roles, including copywriting and art directing (Alvesson, 1998). Furthermore, another crosscultural study looking at the United States and Spain, found similar trends in both countries noting that "creative departments are highly masculine environments, embodying the hallmarks of a 'boys' club'...Creative departments are defined by hegemonic masculinity, framed by sports, humour and clubbing. In essence, they are the men's 'locker room"' (Grow et al., 2012, p. 661). According to another study that conducted in-depth interviews in Canada and the United States, statistical analyses indicated that women only make up 20-25 percent of creative staff (art directors, copywriters, creative and executive creatives) within creative departments, and this has been consistent since 1990 (Grow \& Broyles, 2011). Furthermore, Gregory (2009) reports that, "In 2000...copywriting and art directing were still male dominated at 83 and 
86 percent, respectively, and that these figures represented a proportional decrease in the numbers of women from 1990 to 2000" (Gregory, 2009, p. 331).

Some of the past research discusses how certain changes in the industry may impact the vertical mobility of women in creative advertising and their entrance into higher roles. For example, the Swedish advertising industry has largely changed over time, from a small industry with a few large firms, to a more diverse industry with multiple small firms; this change has been beneficial to women in offering more opportunities for managerial positions and self-employment (Arnberg \& Svanlund, 2016). However, other research indicates that not much has changed to benefit women, creating inconsistencies in the literature. Another cross-national study that looks at 50 countries across the globe refers to the shockingly unequal status of females in managerial positions in creative advertising departments as "vertical segregation" (Grow \& Deng, 2014). The authors contend that "vertical segregation might be contextualized with the principle of male primacy, which holds that men are 'more status worthy than women' and accordingly more appropriate for positions of authority and domination" (Grow \& Deng, 2014, para. 7). Some of the literature indicates that when women enter into more creative roles, many are leaving their jobs prematurely or being phased out of the industry before achieving higher positions (Grow et al., 2012). As explained by Grow and Broyles (2011), "There is a visible fallout of women who graduate from advertising programs and fail to make it any further than five years into their career. By the time one reaches the top, creative women have all but vanished" (n.p.). This trend often results in a lack of women in higher up, managerial positions in the creative advertising industry (Gregory, 2009). In Gregory's (2009) study, the author explains that "women only account for 9 
percent of agency management positions, which include chair, chief executive officer and managing directors" (Gregory, 2009, p. 331).

In addition to case-studies, cross cultural and statistical analyses, the literature draws on several different theories, including Hofstede's dimensional model of national culture (Grow et al., 2012), signalling theory (Grow et al., 2012), and Czikszentmihalyi's systems theory of creativity and sociologically based multidimensional model of sex segregation (Grow \& Deng, 2014). Hofstede's model (2010) was the most commonly drawn upon theory across the literature and I found his dimensional model to be most applicable to this area of study. In the existing literature, Hofstede's model outlines five dimensions: "power distance, individualism versus collectivism, gender dimensions, uncertainty avoidance and long versus short-term orientation" (Grow et al., 2012, p. 658). Grow et al. (2012) use Hofstede's model here to examine how different cultural environments in the advertising industry in different global economies may serve to shape the experiences and roles of women (Grow et al., 2012).

\subsection{Internal and External Factors Contributing to Gender Disparity}

As discussed above, women in the advertising industry have faced several challenges and barriers, which have created a large gender gap in the creative advertising industry. Grow and Deng refer to these barriers as part of a larger process called horizontal segregation also referred to as "the 'glass wall' [which] describe[s] the horizontal barriers that preclude women or men from certain occupations based on gender 
dominance" (Grow \& Deng, 2014, para. 8). For the purposes of this paper, this horizontal segregation refers to the obstacles, both internal and external, that limit the percentage of women in creative advertising departments and deter females' success in this industry, ultimately leading to a prominent gender disparity.

There are many significant internal factors that influence the trajectory and roles of women in creative advertising departments globally. Firstly, researchers have suggested that the culture and structure within many creative advertising departments fosters a "boys' club" mentality (Grow et al., 2008); this consequently makes the socialization and assimilation process into these creative departments more challenging for women. According to authors Grow and Broyles (2011), "Creativity itself is not gender specific. Rather, it is social and environmental constraints that appear to impact the practice and production of creativity" (n.p.). Furthermore, this creates a subculture of sexism both in the industry and within advertisements themselves, which ultimately undermines the roles of women (Mallia, 2009). One aspect of this boys' club manifests itself in males making fun of, or degrading females in a sexual manner. For example, as Gregory (2009) explains:

Those who create advertisements - "creatives" - argue that a "masculine" sense of humour, which sometimes includes the sexualization of women and the use of gender stereotypes is necessary to create successful advertisements...therefore a preference for male humour constructs the product or service and becomes an occupational advantage for creative men. (p. 328) 
Another way that this sexist mentality is manifested is through the males in creative departments making explicit sexual comments towards or about women, which is not only undeniably offensive, but "lessens women's power in the [advertising] workplace and...women are denied advancement if they do not comply with men's sexual requests" (Gregory, 2009, p. 329). The treatment towards, and sexual discussion surrounding women in creative advertising departments can be detrimental to women in this industry. As Gregory (2009) asserts, “The sexualisation of female colleagues is still listed as a primary reason why women constitute a small percentage of creatives" (p. 335). This boys' club mentality extends well beyond men joking around with one another in creative departments; this outlook manifests itself in the physical creation of products and campaigns, often resulting in the degradation of women in various advertisements (Gregory, 2009). The sexual and demeaning nature in which women are often depicted in advertisements further reinforces female creatives' lack of voice and inhibits their ability to express their opinions to their fellow, male-dominated creative team. Furthermore, this boys' club mentality often leads to a gendered segregation amongst creatives, resulting in the assigning to men of "masculine" accounts, and to women of "feminine" accounts. As another author explains, "[women] appear to be trapped in a pink ghetto, especially when limited to working on female products such as those related with beauty, cleaning and children" (Roca et al., 2016, p. 1009). While women are often limited to these more "female" accounts, men are encouraged to work on more "male" accounts, such as cars and beer products. As these socially constructed stereotypes are reproduced in creative departments they become ingrained occupational stereotypes (Grow \& Broyles, 2011), 
ultimately demonstrating "how entrenched locker room masculinities are in creative cultures" (Gregory, 2009, p. 339).

Furthermore, this male-centric dynamic goes beyond agency culture, extending into the places that male creatives choose to gather and conduct business outside of the office, such as bars and strip clubs - places that often implicitly or explicitly exclude women (Gregory, 2009; Roca et al., 2016). Since females often lack accessibility to this network, this has far reaching consequences, including fewer females being selected onto large accounts and fewer women becoming creative directors (Roca et al., 2016).

Of course, since there are so few women in creative roles, there is a lack of visibility of powerful women in the industry, including few creative directors, chief creative officers and few female judges chosen for advertising awards shows (Grow \& Broyles, 2011). According to signalling theory, because of the invisibility of other women in the industry, it becomes difficult to hire and sustain women's roles in the advertising world (Grow \& Broyles, 2011). Further, management, organizational behaviour and communication processes also contribute to the problem. Since managers strive to hire people that are similar to themselves and most powerful people in this industry are men, women get weeded out from the start (Mallia, 2009).

In addition, both external and internal factors such as social expectations and the systematic structure of the labour market, specifically in the United States and Canada, also serve as barriers for women to succeed in creative departments. Two significant social factors that affect women in this field are family life and motherhood. Within advertising agencies, creative departments often do not foster a family-friendly environment; inflexible, long work hours and lots of travel contributes to a highly 
demanding, cutthroat industry making it extremely difficult for women with children to dedicate time to their family (Grow \& Broyles, 2011). Some countries are better than others when it comes to systematic social policies affecting women, ranging largely depending on the country and the particular policy. For example, in Canada, some workplaces allow for a year of parental leave without penalty or part-time arrangements, which positively impacts females; the United States, on the other hand, is often much more intense and does not offer as many lenient options (Mallia, 2009). Contrarily, other Canadian policies serve as large barriers to females in the workforce. For example, as Loriggio (2011) explains, "The lack of accessible, affordable childcare [in Canada] is keeping women from fully participating in the workforce" (para. 2). Another systematic factor impeding the success of females is the issue of the double-day of labour for women. For example, the article "Who are the women in the labour force?" (2010) discusses this issue in Canada and contends:

While men are doing more housework and care for dependents than they have in the past, it is still the case that more women pull an infamous 'double work day' of paid labour followed by unpaid labour in the home than men do. (para. 16)

Other issues surrounding working women and the family include: "the support a women receives from her supervisor and peers...support for breastfeeding within the workplace; flexibility of work hours on return to work; and family leave options" (Nowak et al., 2013, p. 120). Several of these factors impede the ability of females to succeed in several different occupations around the world, and the creative advertising industry is no exception. 
Female creatives' social capital and skill-set outside of their job description affects their role in the workplace as well. For example, organizational politics, the ability to self-promote and deploy one's own leadership skills in the agency all contribute to the achievement of upward mobility in creative advertising (Mallia, 2009). Making strong connections and networking, inside and outside of the agency, in addition to winning industry awards and gaining publicity in the press, all contribute to moving up, getting promotions, raises and better jobs (Mallia, 2009). Psychological factors also influence this development and authors have argued that when it comes to self-promotion and negotiating (Mallia, 2009), independence and self-direction (Proudfoot et al., 2015) these skills come more naturally to men. While women rate highly on openness to experience and divergent thinking, females are often less inclined to self-report and self-promote certain accomplishments, whereas men tend not to have this inhibition (Grow \& Broyles, 2011). The perception of creativity comes into play here, as Proudfoot et al. (2015) claims:

Popular understandings of [the] creative thought process link it to the concept of 'divergent thinking' - a method by which creative solutions are reached via consideration of perspectives that diverge from norms...this masculinized agentic orientation is, in many ways, akin to a divergent type of responding to the world and closely resembles popular understandings of creative thinking. (p. 1752)

Therefore, if a given society views males as more creative than females, it may subconsciously serve as a barrier to entry for women trying to break into this field and impede the ability for females to move up in this industry. 
Lastly, one's personal characteristics and personality contribute to the gender gap as well. Speaking up, persevering, showing confidence and expressing ideas (Grow \& Broyles, 2011) are more challenging in an environment made-up primarily of men, making it more difficult for women to break through these gendered boundaries.

\subsection{Overcoming Barriers and the Gender Divide}

While there are many women that have been affected by these challenges in the creative advertising world, there have been some females (though few in number) that have overcome these barriers and successfully tackled this gender divide. The literature in this area often uses the methodological approach of in-depth interviews with top creative women and creative directors. In one study, interviews were conducted in four geographical locations - The United States, The UK, Canada and South Asia - and spanned a range of different environments, from large firms to smaller agencies (Mallia, 2009). The research highlights the differences between those who stayed in the industry and those who rose to the top, versus those who were phased out or left. The literature explains that women who flourished in the industry did more things "like men" (Mallia, 2009). For instance, with regards to family life, the women that were interviewed didn't have spouses in equally demanding positions or did not have children. If children were present, the men often stayed at home with the kids (Mallia, 2009). Furthermore, the women who rose to the top were able to adapt to organizational politics early in their career, and understood early on how one gains power in the advertising industry (Mallia, 2009). For instance, one of the creative directors stated, "You have to be a very valuable 
asset. Unless you are a valuable asset, unless you count for dollars, it doesn't matter. It doesn't matter what sex you are" (Mallia, 2009, n.p). Beyond this, Cheow and Chaldaroon (2016) express the importance of adapting "soft" thinking skills in the creative advertising industry. This includes metaphorical and paradoxical thinking, ambiguous thinking and fantasy thinking, instead of analytical thinking (Cheow and Chaldaroon 2016). This higher order thinking is difficult to achieve for many because of the mental and physical energy that it requires. Additionally, Mallia (2009) explains that having strong client relationships is incredibly important in order to develop a strong network and form deep connections with others. Moreover, in terms of personality, the more aggressive, persistent and competitive females were more likely to succeed (Mallia, 2009). The interviewees expressed extreme internal motivation and described the incredible sacrifices they made for their careers. For example, in one study a respondent explained:

I've always worked no matter what. I mean my mother managed to die over Christmas so I didn't miss any assignments. I don't think I've ever-even when [my husband] was in the hospital for seven weeks, I managed to not take a day off. I'd go visit him at the end of the day...I've given up my life in a way. But it's okay. (Mallia, 2009)

Lastly, women expressed that their work satisfaction and ability to rise up was largely dependent on the type of agency they were working for. Women in smaller agencies had an easier time overcoming these barriers, whereas larger industries, such as 
New York's advertising field, is much more difficult to break into and rise to the top (Mallia, 2009).

Other studies offer insightful advice on the steps female creatives can actively take in the industry in order to overcome these gender barriers. A study of creative women in Peru, for instance, discusses the importance of having a zero-tolerance policy for sexism in the agency and actually calling it out when it occurs (Grow \& Torras, 2015). Additionally, researchers suggest having more mixed gender teams in order to eliminate "girly or female accounts," thus allowing more room for flexibility for both sexes and to stop glorifying all-nighters, catering instead to those with outside family lives (Grow \& Torras, 2015). 


\section{4) DATA COLLECTION AND METHODS}

Using a qualitative data approach, this MRP was informed by previous research discussed in the literature review and further developed using data collected from three media sources (Art \& Copy documentary, Mad Men television series and The 3\% Conference) in order to answer the second research question which asks how different media sources portray women in creative advertising. The reason for choosing these three media sources is because each one has a different purpose and engages the issue of few women in the creative advertising industry from a different perspective; Mad Men serves to entertain, Art \& Copy's objective is to educate and entertain, while The 3\% Conference attempts to achieve political mobilization in the advertising industry on a global scale. Another reason why the media source Mad Men was chosen is because it is the series' tenth anniversary (Framke, 2017), and therefore, the show has become even more prominent in the media lately. All three of these sources derive from North America, although their scope and influence may affect viewers outside of the continent, reaching audiences worldwide. This data was collected manually for all sources, with the exception of The 3\% Conference - that data was accessed using the online tool Keyhole. Keyhole was chosen as it is extremely easy to use, creates fast results and offers several different dimensions to look at, including: users, posts, reach, impression, demographics and sentiment. This MRP employed a qualitative approach, as the data collected is qualitative and will subsequently be analyzed and counted based on certain criteria listed below. A convenience sample, a type of non-probability sample, was chosen for this MRP because the data is easy and fast to obtain, is inexpensive and is readily available. 
The data for the literature review was easily accessible through online databases and the Ryerson library database, while the media sources were able to be analyzed online as well. The data from Keyhole was easily obtainable, however, the challenge was that this online tool only allowed data collection over an eight to ten-day period. Therefore, in order to diminish this issue, I took a data sample from Keyhole over two time periods that were approximately three months apart in order to gain a longer period of data, and therefore, a larger sample. This sampling method allowed me to obtain data in this area of study and gain insight into the issue of why there is such a small percentage of women in creative advertising departments, globally. Furthermore, these findings may be used for a potential, larger follow-up study. The time frame for collecting the Keyhole data ranges from March $9^{\text {th }}$ to June $24^{\text {th }}, 2017$.

A content analysis was also employed in this MRP, which was informed by an extensive literature review. The literature review used to answer the first research question offers insight into the numerous factors that may contribute to the gender disparity in the creative advertising industry. The existing literature relies on several different methodologies, theories and offers different findings, allowing for a broad, multi-dimensional view of this issue. My objective was to gain a more accurate picture as to why there are have been so few women in creative advertising historically, on a global scale.

The content analysis was executed in this MRP for the purpose of analyzing both visual and textual content from the three media sources: Art \& Copy, Mad Men and The $3 \%$ Conference; for the former two, the data was collected manually, through a visual content analysis, while for the latter source, the online tool Keyhole was utilized to 
execute a textual content analysis. This content analysis is considered to be an inductive approach, as the MRP looks at three small media sources, to answer the broad, second research question of how popular culture portrays women in advertising.

Firstly, for the Art \& Copy documentary, data was collected between March $9^{\text {th }}$ and April $9^{\text {th }}, 2017$. This data was collected using a qualitative approach because the data is in qualitative form (visual images, film and language). This data was collected manually by watching the documentary and jotting down notes on specific criteria throughout the film.

Secondly, for Mad Men, I watched the first episode of the first season "Smoke is in your eyes" (Weiner \& Hunter, 2007) and the last episode of the final season "Person to person" (Weiner, 2015) between March $16^{\text {th }}$ and April $16^{\text {th }}, 2017$; the reason for choosing these two episodes was to gain an understanding of how the show develops over time from the season premiere in 2007, to the show's finale in 2015. The data collection approach for these episodes was conducted manually, in the exact same way as Art \& Copy in all respects; however, it was done twice, after watching two different episodes.

For both Art \& Copy and Mad Men, a visual content analysis was employed based on four elements: the roles of women, the sexualization of women, the degradation of women in the advertising industry and the focus on men. These four elements were chosen because they allowed me to gain insight into the number of women in certain roles, to learn how women are treated in this industry and how male dominance influences women's positions, as portrayed by the media. The roles of women were measured along two dimensions: firstly, by analyzing the number of women in roles outside of creative departments (secretarial, accounts or strategy positions) and the 
number of those within creative departments. Secondly, the roles of women were analyzed along the dimension of the number of women in top positions (creative directors, managers and owners). Additionally, the sexualization of women was measured in Art \& Copy and Mad Men along two dimensions: language and actions in the advertising industry. Any sort of sexual language used towards women in the advertising industry within the film and series was assessed, including comments about a women's physical appearance, her sex life or any other comment that is sexual in nature. Additionally, the general sexual actions displayed towards women were measured, analyzing both non-contact sexual or seductive actions (i.e. licking lips, winking, staring inappropriately at a women's body parts and so forth) and contact sexual actions (i.e. slapping a girl's bottom, kissing her or sleeping with her) within the agency setting. Further, the degradation of women was measured based on any demeaning language and actions towards women. Lastly, the focus on men was measured by the roles of men (inside and outside creative departments, and higher-up roles) as well as the fostering of a boys' club mentality, both inside and outside the office, both in language and action. This visual content analysis allowed me to assess where the majority of women's and men's roles lie, and whether the language or actions towards women in the advertising industry are sexualized or degrading in nature, as depicted by this media source. This in turn, shed light on the second research question, regarding how different media sources portray women in the creative advertising industry, which offered further insight into the first research question of why there are so few women in the creative advertising industry today. 
Thirdly, for The $3 \%$ Conference, the hashtags from two online social media platforms, Twitter and Instagram, were studied over two different time periods: March $20^{\text {th }}$ to March $29^{\text {th }}, 2017$ and June $17^{\text {th }}$ to June $24^{\text {th }}, 2017$. The reason these two time periods were chosen was because Keyhole only offers approximately 8-10 days of data at a time; therefore, by choosing two different time periods that are three-months apart, I was able to draw data from a three-month window of 2017. I tracked these hashtags from approximately the beginning of March until the end of June 2017 to assess the popularity and usability of these hashtags on different social media platforms, shedding light on whether there had been heightened awareness of this issue during three months of 2017 through outreach on social media since the movement began in 2008. A textual content analysis was utilized by examining two different hashtags used by The 3\% Conference: \#3percentconf and \#changetheratio. Keynote was used to analyze these hashtags on both Twitter and Instagram, and generated findings of the number of posts, users, reach and impressions. Furthermore, by analyzing these two hashtags used over approximately a three-month period, Keynote analyzed the percentage that each hashtag was used per country, the percentage of males and females using this hashtag (demographics) and whether the hashtag was used in a positive, negative or neutral manner (sentiment). This analysis offered an estimate of the number of individuals globally who have used and shared this hashtag. This shed light on how The 3\% Conference reached individuals through social media worldwide, how many individuals became aware of and responsive to this problem, and whether this movement has made a difference in this gender disparity in creative advertising. These finding ultimately helped to answer my second 
research question of how the media engages with this issue of few women in creative advertising through social media platforms.

I then compared the results of the visual and textual content analyses, against the findings in the literature review, to gain insight into my third research question of whether the depiction of women in creative advertising in popular culture aligns with the historical facts presented in the literature. This will be further discussed in the following section. 


\section{5) FINDINGS AND DISCUSSION}

\subsection{Visual Content Analysis}

A visual content analysis was executed by watching the first episode of Mad Men "Smoke is in your eyes" (Weiner \& Hunter, 2007) and the last episode "Person to person" (Weiner, 2015) of the final season. The two episodes were analyzed along four dimensions: the roles of women (inside and outside of creative departments), the sexualization and degradation of women in the advertising industry (through action and language) and the show's primary focus on men (based on their roles and the 'boys' club' mentality) at the fictional advertising agency, Sterling Cooper. In the first episode, there were ten women depicted outside of creative departments and none depicted in creative positions. Additionally, there were only two women shown in a higher-up position, however, neither were part of the creative department; one was mocked and treated disrespectfully and the other was the office secretarial manager (though the latter women is shown in a managerial position, it is not necessarily considered a respectable role by the men at Sterling Cooper) (Weiner \& Hunter, 2007). Additionally, the sexualization and degradation of women were analyzed through language use and action towards women in the advertising industry throughout the episode. In the first episode "Smoke in Your Eyes", eight sexual comments and six demeaning comments were made by men towards women; there was also one sexual comment and one demeaning comment made from one man to another and seven demeaning comments made by one woman to another. For example, one of the sexualized comments made by 
Campbel (a male in the accounts sector at Sterling Cooper) to the new secretary Peggy Olson went as follows:

Where are you from, are you Amish or something? You're in the city now, it wouldn't be a sin for us to see your legs. If you pull your waist in a little you may look like a woman...hey, I'm not done here, I'm working my way up. (Weiner \& Hunter, 2007)

Another example of demeaning language was the way Donald Draper, the advertising agency's creative director, spoke to his female client, "I'm not going to let a woman talk to me like this. Good luck Miss Megan” (Weiner \& Hunter, 2007). Finally, a few more surprising examples included the demeaning language that was used from one woman speaking to another about her duties towards her male boss, Donald Draper: "He may act like he wants a secretary, but most of the time he's looking for something between a mother and a waitress, and the rest of the time, well..." insinuating that the men at the agency are looking for sex (Weiner \& Hunter, 2007). Another example of this nature is how Joan Holloway, the secretarial manager, speaks to the new secretary Peggy Olson: "Try not to be overwhelmed by all this technology; the men who designed it made it easy enough for women to use" (Weiner \& Hunter, 2007). The latter comment is inherently sexist and completely undermines the capabilities of women, suggesting that men are far more competent and intelligent.

Additionally, there were two non-contact seductive actions that took place, one of which included men 'checking out' the new, good-looking female employee (Weiner \& 
Hunter, 2007). There were no physical sexual actions inside the workplace, however, there was a sexual encounter between two Sterling Cooper employees outside of the office, initiated and arguably manipulated by a man (Weiner \& Hunter, 2007). There was one degrading gesture that was made as well (Weiner \& Hunter, 2007).

In the last episode of the last season of Mad Men called "Person to Person", there were three women in higher up positions, one of which was inside the creative department and two women in secretarial roles. There was one sexual comment made by a man towards a woman, and one demeaning comment made as well, with no sexual actions (Weiner, 2015). One of the demeaning comments made by a man towards the high-up, female creative was, “Keep it up and you'll be a creative director by $1980 .$. they just have to get used to the idea" (Weiner, 2015). While this comment on its own may sound like a favourable, encouraging phrase, in the context of an entire industry where men largely dominate women and where it is highly unlikely for women to hold high positions of power, this phrase can be seen as sarcastic and detrimental to the progress of females.

The focus of men in the Mad Men episodes was measured based on the dominance of men in higher-up roles and respectable positions in the agency and the fostering of a boys' club mentality both inside and outside of the office. The title of the show itself, Mad Men, is indicative of the series' overall focus on men, primarily, the show's protagonist and extremely successful creative director, Donald Draper. In the first episode, there were three men portrayed in creative roles as (a creative director, an art director and a copywriter), three in high power positions, two in accounts, one media buyer and none as secretaries. While there are only three males shown in creative roles, 
all the positions that the men in the episode hold are portrayed as respectable.

Furthermore, the agency culture at Sterling Cooper fosters a boys' club mentality, very much in line with the previous literature, where men are constantly drinking, smoking cigarettes, sexualizing women and outside of the office, meeting at bars and strip clubs. Some of the comments that nurture this mentality and male culture are: "Should we drink before the meeting, or after, or both" and "I see that you guys are about to engage in some mid-level comradery, so I'll be on my way" (Weiner \& Hunter, 2007). Furthermore, in the first episode, the office men attend a bachelor party at a strip club together where they engage in flirtatious and sexual contact with other women, including one of the account men rubbing another women's leg. In the last episode, most of the episode consists of roles outside of the office, but we still see two men in creative positions and one man in a high up role, as well as one woman. While these areas largely progressed from the first episode to the very last, men still significantly outnumbered women, females were generally not respected as equals and very few women held high positions of power, or resided within the agency's creative department. However, the two characters that did show a huge progression were Peggy Olson - who moved up from Donald Draper's secretary in the first season, to a creative copywriter with her own office in the last - and Joan Holloway who started as an office manager and later started her own production company (Framke, 2017). Both female characters made their way up in the industry by speaking up for themselves, fighting for what they believed in and had confident and dominant personalities, or at least 'faked it until they made it' to the top. This trajectory is in line with the scholarly literature as well, which explains that the women who made it to the top or who persevered in the industry, showed more 
assertiveness and confidence in their abilities (Mallia, 2009), shedding light on the third research question of how the findings align with the facts presented in the literature.

A second visual content analysis was executed by watching the hour and a half long documentary Art \& Copy. The results were much more positive for Art \& Copy than for Mad Men; in the former, there were no incidences of sexualization or degradation of or towards women in the form of action or language, whereas in the latter there were quite a few. There were two comments that were flagged as potentially sexist, as the comments surrounding the advertising industry are described by men and use solely masculine pronouns. For example, one of the creative partners in the documentary explains:

Adman was the account guy at the beginning; always wearing a suit...the account guy was the one that was important. If you want to be an ad-guy, you have to be an account guy, wear the vest and tie...creative wasn't big [at this time]. (Greenway, Nadeau, \& Pray, 2009)

This male in Art \& Copy is speaking very generally about an industry that should be inclusive of both sexes, yet females are completely excluded from this commentary, which is extremely problematic. However, a counterargument to this is that while this may be a form of covert sexism, this may not be considered overt sexism, nor sexism intended to exclude or offend women. Nevertheless, it is exactly this form of covert sexism that may influence the lack of visibility of women in the advertising industry, which sheds light on the research question of which factors may affect women entering 
the industry, and the second question of how the media portrays women in creative advertising. Speaking to the third research question, this form of covert sexism depicted in the documentary is in line with the facts in the literature of how women are often excluded from high positions and certain big accounts as well (Roca et al., 2016; Grow \& Broyles, 2011). Therefore, it is crucial that different media sources, particularly one that is striving to educate the public about a particular industry such as $A r t \& C o p y$, pay special attention to these seemingly small, but crucial components of sexism that are subtly imbedded within their film.

Additionally, despite there being less sexualization and degradation of women in the documentary than the TV series, there were still only three women in top roles in Art $\&$ Copy, only two of which were within the creative departments. While this is an improvement compared to the television series Mad Men, these women were still largely outnumbered by the nine males in the documentary who held both creative and high-up positions (Greenway, Nadeau, \& Pray, 2009). These findings strongly align with the observations found in the literature, which describe how males still outnumber their female counterparts, both in managerial and creative positions, despite the small progress that has been made.

These media sources together lend insight into the second research question of how the media portrays women in advertising. While the Mad Men episodes (especially the first) denote a mainly negative, sexist portrayal of women in the advertising industry, Art \& Copy offers a more positive depiction of women in creative advertising departments and in higher roles. This contrast may have serious implications for the role of women in creative advertising in real life, shedding light on the third research question 
of whether the portrayal of women in creative advertising in popular culture offers a reliable depiction of the historical nature of women's roles, as discussed in the literature. This discrepancy may speak to the purpose of each media source itself. Since Mad Men's primary incentive as a television show is to entertain viewers, the show may purposely include more stereotypes, exaggerations and overtly sexist comments and actions towards and about women, especially in the first episode. Contrarily, Art \& Copy strives both to entertain and educate viewers. As a documentary, Art \& Copy may more accurately represent the roles of women in the industry in real life; however, this would contradict the existing research, which suggests that advertising agencies oftentimes foster a boys' club environment (Grow et al., 2012) that is exclusive to women. However, although Art \& Copy depicts more women in leading roles and in creative departments than Mad Men, men still largely outnumber women in the film, specifically within creative departments and managerial positions. Another reason for this variance may be that while Mad Men offers a 1960s portrayal of the industry (though filmed between 2007 and 2014), Art $\&$ Copy, released in 2009, offers a historical view of the advertising industry on a broader scale, but through a contemporary lens. The importance of the year in which the sources were filmed and the era they represent is extremely relevant, as certain social expectations begin to shape certain roles in the film and series. According to Marcotte (2013), "the pressures of shifting gender roles affect all characters [in Mad Men], from the aspiring businesswomen to the happy homemaker, and, of course, their male counterparts, who don't know how to handle the erosion of male dominance" (para. 1). In Mad Men, from the first season shot in 2007, to the last in 2014, more females enter into higher-up positions and are more well respected by their colleagues, mirroring the 
progression of women's rights and heightened feminist ideals that rose from the early to late 1960s. As Framke (2017) notes:

For as much as Mad Men was about the cyclical frustrations of petty men, it was also about the determination and creativity of women. Just as much as Mad Men knew Don Draper would never change, it discovered that its women - especially Peggy and Joan - were destined to take the kinds of journeys he never could. (para. 6)

However, despite the large progression of two female characters - Peggy Olson and Joan Holloway - gaining respectable, creative positions by the series' finale, this is not the case for most women at the agency and females are still largely outnumbered by men, thus aligning with the literature. Another article on Mad Men contends, "Despite its title, Mad Men is as much a show about the dramatic changes in women's lives in the 1960s as it is about those men" (Marcotte, 2013, para. 1). Therefore, perhaps Mad Men may not focus predominantly on men, but rather on men occupying high positions of power, both within the creative departments and outside, and the challenges that women face in trying to move up and succeed in this industry.

Additionally, this progression of females may also align with and reflect the time period that Mad Men's director lives in, rather than the decade that the show itself represents. It may be the political leaning of both Art \& Copy and Mad Men's writers and directors to portray women in the film and the last season of the show in a more positive light, so that they (the creators of the series and documentary), are viewed as moral and 
high-minded individuals by today's viewers and reviewers. Perhaps, then, Art \& Copy and the later episodes of Mad Men may truly be a less accurate version of the truth, and consequently, do not align with the facts presented in the literature, but instead, speak more to the biases of the directors and contemporary cultural expectations surrounding women's rights, equality of the sexes and feminist ideals.

Furthermore, the women that were able to surpass this gender divide and break into high-level creative positions, both in Mad Men and Art \& Copy, demonstrated more assertiveness and confidence, acting similar to their male counterparts. This latter finding strongly correlates with the literature as well, which suggests that an assertive personality matters a great deal for women who make it to senior roles (Mallia, 2009). This media portrayal of women as bold and self-assured beings (or not!) has strong implications for the roles of women in real life, and has the potential to truly inspire and empower women who are fighting to make it to the top in this industry. On the other hand, this depiction of only those women who are extremely strong-willed making it to the top, versus their more complacent, male creative bosses may be problematic as well. It is crucial to ensure that these small, seemingly unimportant depictions of females, both in fictional television shows and non-fictional documentaries, are addressed and closely analyzed before displaying them for the world to see if greater gender equity in the advertising industry (or any workplace) is to be achieved.

\subsection{Textual Content Analysis}


A textual content analysis was used to observe the hashtags \#changetheratio and \#3percentconf, used by The 3\% Conference, between March $20^{\text {th }}$ until March $29^{\text {th }}$, and again between June $16^{\text {th }}$ and June $24^{\text {th }}$. The first group of data was collected between March 20 and March 29, 2017. Keynote generated the results from March $20^{\text {th }}$ and March $29^{\text {th }}$ for the hashtag \#changetheratio on Twitter, indicating that there were 368 posts, 225 users, with a reach of $1,033,844$ and 3,688,855 impressions ("Keyhole: Hashtag\& Keyword Analytics", 2017). A large majority of the responses (76.01\%) were from the United States, with smaller percentages in Australia (6.76\%), the United Kingdom (6.08\%) and Canada (3.38\%) (“Keyhole: Hashtag \& Keyword Analytics”, 2017). The demographics showed that the large majority of those who shared the hashtag were female (78.4\%), while only $21.6 \%$ were male (see figure 1a). The majority of the posts were attached to a neutral sentiment (66.5\%), while $29.5 \%$ were positive and $4.0 \%$ negative (see Figure 1). The \#changetheratio hashtag on Instagram generated far fewer results: 127 posts, 46 users, with the majority in the US (75.6\%) ("Keyhole: Hashtag \& Keyword Analytics”, 2017). Surprisingly, all hashtags were used by females here, and offered a more positive sentiment (see Figures 2 and 2a). The \#3percentconf generated negligible results in comparison on Twitter, results indicating only 3 users, 3 posts with a reach and impression of 581 . Half of the \#3percentconf hashtags were in Canada $(50 \%)$ with half in the United States (50\%), half were female (50\%) and half male (50\%), with a majority having a positive sentiment (66.7\%) (see Figures 3 and 3a). Instagram surprisingly showed zero results for this hashtag.

The second group of data was collected between June 17 and June 24, 2017. Keynote generated the results for the hashtag \#changetheratio on Twitter, indicating that 
there were 329 posts, 250 users, with a reach and impressions over 100,000. The highest percentage of posts were in the United States at $60.67 \%, 15.33 \%$ in the United Kingdom, $3 \%$ in Switzerland, $2.67 \%$ in Canada, $2 \%$ in Italy, $1 \%$ in France, Argentina, $0.67 \%$ in Sweden, Finland, South Africa and Australia, and $0.33 \%$ in Venezuela, Peru, Germany, Bulgaria, Denmark, Nigeria and the Philippines (Keyhole: Hashtag \& Keyword Analytics", 2017). The demographics showed that the majority of those that used the hashtag were female (88.7\%), while only $11.3 \%$ were male (see Figure $4 a)$. The sentiment depicted that $65.6 \%$ was neutral, $33.4 \%$ was positive and $1 \%$ was negative (see Figure 4). Furthermore, the hashtag \#changetheratio on Instagram generated fewer results, with 86 posts and 53 users (Keyhole: Hashtag \& Keyword Analytics”, 2017). The countries that used the hashtag were limited as well, with $67.85 \%$ in the United States, $10.71 \%$ in the United Kingdom, $7.14 \%$ in France and $3.57 \%$ in South Africa. Again, the demographics were mainly female (76.9\%), while $23.1 \%$ were male (see Figure $5 \mathrm{a}$ ). The sentiment for this hashtag was $72.9 \%$ positive, $20 \%$ neutral and $7.1 \%$ negative (see Figure 5). Additionally, for the hashtag \#3percentconf on Twitter, the results were negligible with only 2 posts and users, a reach and impressions of 19,724, with the United States being responsible for $100 \%$ of the hashtags. The sentiment of the posts is completely positive (see Figure 6), and the demographics data is unavailable. The results for the hashtag \#3percentconf on Instagram are also very small, with only 3 posts and 3 users, no data for countries using the hashtags or demographics and $100 \%$ positive sentiment (see Figure 7).

These results from both datasets have significant implications that offer insight into the second research question of how the media portrays females in creative 
advertising. From this textual content analysis, it is evident that the Twitter hashtags for The 3\% Conference are used significantly more often than the Instagram hashtags and that the hashtag \#changetheratio is significantly more popular than \#3percentconf. This indicates that Twitter may be a more successful platform to generate awareness and reach using hashtags to a variety of audiences worldwide than Instagram. Additionally, this analysis reveals that the greatest percentage of people sharing this hashtag are from the United States, oftentimes with the United Kingdom as a runner up, while a very small percentage of other countries worldwide share this hashtag. This is significant because according to the literature review, this gender gap in creative advertising is a worldwide problem, and consequently, requires worldwide attention. However, a problem with using social media to generate awareness of this issue is that not everyone in the world has easy access to it; a counterpoint to this is that even other developed countries that do have access to social media such as western Europe, Canada, and Australia, are not sharing the hashtag nearly as much as users in the United States. Although the most probable reason for this is that The 3\% Conference began in the United States, the movement's website and hashtags are available worldwide, seeking global recognition. Furthermore, females shared the majority of these hashtags, which is significant because the issue of few women in creative advertising is a problem that affects society at large. However, the fact that more females are sharing these hashtags on Twitter and Instagram than men may be indicative of more women using these social media platforms, rather than more women caring about this issue. Additionally, most people using the hashtags on both platforms have either a positive or neutral sentiment, with a very small percentage having a negative connotation. The high number of positive sentiments associated with this 
hashtag is a great sign as people are associating the hashtags, and the idea and need for change, with favourable ideals or at the very least, take an impartial stance on the issue. Indeed, perhaps if people were more strongly in favour of and associated the hashtags almost entirely with positive ideals, then there would be more progress made in terms of more women in creative advertising and the ability for women to occupy high-up, managerial positions in this industry. 


\section{6) LIMITATIONS AND FUTURE RESEARCH}

This masters research paper examined the broad question and problem of why there are so few women in creative advertising departments both in North America and on a global scale, by focusing on three specific questions: 1) Why have women historically made up such a small percentage of creative roles in the advertising industry globally and which factors may contribute to this development?; 2) How do different media platforms (film, television and online movements) portray women in creative advertising in North America?; and 3) Does the portrayal of women in creative advertising in popular culture offer a reliable depiction of the historical nature of women's roles, as discussed in the literature? While this paper offers a range of insights into this issue, it does not attempt to provide a definitive or conclusive answer to the complex question of why this gender gap persists in the field of creative advertising. Rather, by looking at the historical trajectory of women in the industry, examining how the media portrays female creatives, how a political movement seeks to create change and assessing whether the media and literature align, this helps readers to develop a better understanding of this issue, offers room for future research and hopes to promote change for these women worldwide.

There are a few limitations in this paper that could be further addressed in future research. Firstly, while the literature review in this study looks at a wide variety of sources, due to the confines of the paper, this review is inconclusive and does not come close to addressing all of the past research that currently exists on the issue of few women in creative advertising, few females occupying managerial roles in creative advertising 
departments and few women acting as judges for creative advertising awards shows. Furthermore, the reason that this study did not choose to conduct interviews with women in this industry was twofold: firstly, there is a lot of existing research that uses this methodology, and secondly, these high-up, creative ad-women are difficult to access on a broad, national or international scale. Additionally, another limitation is that due to the confines of this paper, only three different media sources were chosen to assess how women in creative advertising are portrayed in popular culture. That is, other areas of popular culture could have also been selected, such as a different documentary, film, series or movement. Other potential media sources to consider for future research may include, but are not limited to, news and magazine articles, e-books, podcasts, blog posts, and so forth. Furthermore, the specific sources that were chosen for this paper may suffer from the selective bias of the researcher (myself) as they were based both on personal interest and accessibility. Further, two other possible limitations are the validity and reliability of the data. As previously discussed, the creation and depiction of women in Mad Men and Art \& Copy may be largely attributed to the biases of the writers and directors of both the series and documentary; therefore, the accuracy of the data is called into question, as it may not offer an accurate portrayal of women's roles in creative advertising in real life. Similarly, the data that was collected for the textual content analysis for The 3\% Conference was only accessible over a ten day period, on two separate dates, that were approximately three-months apart, rather than the data being consistently collected over a three-month period of time. The reason for this is that the data analytics site, Keyhole, and the many other potential resources that were observed online, only offered data tracking of hashtags for a short time period. Since the dataset is 
very small (only looking at two datasets of ten-day periods that are three months apart), it is questionable whether this provides an adequately accurate picture of the movement's success. For future research, if funding were available, it would be helpful to track the hashtags from the year the movement began in 2008 up until 2017 to provide a more reliable picture of how the movement and awareness of the movement has changed. Furthermore, the purpose of including The 3\% Conference as a data source was to gain insight into whether the movement creates successful awareness of this issue through different media platforms. However, there are many several other potential ways to track this "awareness", such as sending out surveys, media monitoring, conducting focus groups and doing further research. Therefore, the validity of the data is also a potential limitation, since it is difficult to assess whether this method of hashtag tracking accurately helps to answer the question of how much awareness this movement has raised over time. 


\section{7) CONCLUSION}

In conclusion, scholarly literature in the area of women in creative advertising discusses several important trends that help to inform the original research that was conducted in this paper. These trends include: few women in creative advertising departments on a global scale, few females in managerial positions in the advertising industry, women entering into but being phased out of the industry early, and few women being selected as advertising awards show judges (Grow \& Broyles, 2011; Grow et al., 2012; Mallia, 2009). As a result, these trends generate a substantial and problematic gender divide in the creative advertising industry. There are several contributing factors, both internally and externally, that may contribute to this development, including creative departments fostering a boys' club mentality, a lack of visibility of women at the top, several barriers to entry (such as these work environments not being conducive to raising a family), and females' potential lack of assertiveness and confidence in their roles as a result (Grow et al., 2008; Grow \& Broyles, 2011, Mallia, 2009).

After analyzing the three media sources through a series of content analyses in an attempt to answer how popular culture portrays women in advertising, the results indicated that Mad Men offers a mainly negative portrayal of women, with few women in creative positions, barely any females at the top of the profession, and many instances of sexualized and degrading actions and language being used towards females. Art \& Copy on the other hand offers a more positive depiction of females, showing almost no sexual or degrading actions; however, women in this film are still outnumbered in both creative and managerial positions and there are subtle, sexist notations that exist throughout the 
documentary. Lastly, the literature on The 3\% Conference shows that there has been progress made since the movement began in 2008 as the number of female creatives in the United States has risen from 3\% to 11\% ("History \& Highlights," n.d.). While some progress has been made, until this number reaches $50 \%$, this problem should not be put to rest. The textual content analysis of this media source shows that the hashtag \#changetheratio is most commonly used on Twitter, attempting to raise awareness of this problem to audiences worldwide. However, it is mainly females in the United States using this hashtag, leaving out half of the population (of males), and the majority of other countries that lie outside the United States ("Keyhole: Hashtag \& Keyword Analytics," 2017) that could potentially contribute to and help eliminate this problem. The ultimate goal of this movement should seek to ensure that the percentage of female creatives in the United States keeps rising each year, to a higher degree and at a faster pace than it does currently.

After comparing the findings in the analyses to the facts presented in the literature, it is evident that the way the media portrays females, which is often in a negative manner, may impact women in the creative advertising industry in real life. Although there is likely not a direct relation between the two, it is very possible that there is a correlation between how the media portrays women and the ways in which they are socialized into specific roles in practice. Many people recognize this issue and the dire consequences of taking popular culture too seriously; however, individuals often underestimate the ways that the media subconsciously influences how we think, act and interact with one another and the case of women in creative advertising is no exception. 
Though the damage of the past cannot be undone, as we move forward it is imperative for researchers, creative people, managers and the public to acknowledge this issue, to reassess gendered hiring processes and to develop more effective structural and social changes. These structural changes may be implemented through enforced government policies and regulations or a change in the public's spending priorities to ensure that women are being equally treated in the workplace. The public's support of these significant changes will not only help contribute to resolving this gender gap in the advertising industry, but could also go some way to improve the gender disparities in many other fields of work as well. The past century has seen the introduction of some of the most innovative technologies, has seen human rights activists fight for freedom, and seen LGBQT movements change the status of legal marriage in several countries worldwide, and philanthropists and citizens donate vast sums of money to save lives and support innumerable worthy causes; indeed, the world has changed in so many ways that people never previously considered possible. I am confident that if enough people become actively aware of and strive to promote a change around this " 3 percent problem" this gender gap in today's workplaces can, with time, be overcome. 


\section{$\underline{\text { References }}$}

Alvesson, M. (1998). Gender Relations and Identity at Work. Sage Journals, 51 (8), 9691005. doi: https://doi.org/10.1177/001872679805100801

Arnberg, K. \& Svanlund, J. (2016). Mad Women: gendered divisions in the Swedish advertising industry, 1930-2012. Business History, 59 (2), 268-291. doi: http://dx.doi.org/10.1080/00076791.2016.1182158

Cheow, Y. \& Chalderoon, S. (2016). Work-life Harmony for Creative Minds in the Advertising Industry. Journal of Public Relations and Advertising, 9(1), 2-16.

Framke, Caroline. (2017). 10 years ago, Mad Men began a story of men who tried to change - and the women who actually did. Vox. Retrieved from https://www.vox.com/culture/2017/7/19/15992342/mad-men-anniversary-donpeggy-joan

Greenway, J., Nadeau, M. (Producers), Pray, D., (Director). (2009). Art \& Copy [Motion picture]. United States: Art \& Industry.

Gregory, M. R. (2009). Inside the locker room: male homosociability in the advertising industry. Gender, Work \& Organization, 16(3), 323-347.

Grow, J. M. \& Broyles, S. J. (2008). Creative women in advertising agencies: why so few "babes in boyland"? Journal of Consumer Marketing, 25(1), 4-6. doi: http://dx.doi.org/10.1108/07363760810845354

Grow, J. M. \& Broyles, S. J. (2011). Unspoken Rules of the Creative Game: Insights to Shape the Next Generation from Top Advertising Creative Women. Advertising \& Society Review, 12(1).

Grow, J. M. \& Deng, T. (2014). Sex Segregation in Advertising Creative Departments Across the Globe. Advertising \& Society Review, 14(4).

Grow, J., Roca, D., \& Broyles, S. J. (2012). Vanishing acts. International Journal of Advertising, 31(3), 657-679. doi: 10.2501/IJA-31-3-657-679

Grow, J. \& Torras, M. (2015). Creative women in Peru: outliers in a machismo world. Communication \& Society, 28(2), 1-18.

Hashtag Tracking for Twitter and Instagram. (n.d.). Retrieved March 30, 2017, from http://keyhole.co/

Hashtag Tracking for Twitter and Instagram. (n.d.). Retrieved June 24, 2017, from http://keyhole.co/ 
History \& Highlights. (n.d.). Retrieved June 20, 2017 from

http://www.3percentconf.com/about

Loriggio, P. (2011, Mar 07). Economy threatened by need of national childcare plan, group says; report finds lack of accessible, affordable care keeps women from workforce. Trail Times. Retrieved from http://ezproxy.lib.ryerson.ca/login?url=https://search-proquestcom.ezproxy.lib.ryerson.ca/docview/856152662?accountid=13631

Mallia, K. (2009). Rare Birds: Why So Few Women Become Ad Agency Creative Directors. Advertising \& Society Review, 10(3). doi: 10.1353/asr.0.0032

Marcotte, A. (2013, April 5). What Mad Men says about women. The Guardian. Retrieved from https://www.theguardian.com

Marieke, M. \& Hofstede, G. (2010). The Hofstede Model. International Journal of Advertising, 29(1), 85-110. doi: 10.2501/S026504870920104X

Nowak, M., Naude, M. \& Thomas, G. (2013). Returning to Work After Maternity Leave: Childcare and Workplace Flexibility. Journal of Industrial Relations, 55(1), 118135. doi: 10.1177/0022185612465530

Phelps, D. (2014, May 26). THE AD WORLDS GENDER GAP: The Mad Man era is gone but women who are creative directors remain few. Star Tribune. Retrieved from http://ezproxy.lib.ryerson.ca/login?url=http://search.proquest.com/docview/152 9500360?accountid=13631

Proudfoot, D., Kay, A. C., \& Koval, C. Z. (2015). A gender bias in the attribution of creativity: archival and experimental evidence for the perceived association between masculinity and creative thinking. Psychological science, 26(11), 1751-1761.

Thomas, J. (2012, November 15). Interview with Kat Gordon, Founder of The 3\% Conference. Retrieved from https://www.forbes.com/sites/jessethomas/2012/11/15/interview-with-katgordon-founder-of-the-3-conference/\#6f25ea777e67

Weiner, M. (Writer), \& Hunter, T. (Director). (2007). Smoke gets in your eyes [Television series episode]. In W. Bros (Producer), Mad Men. United States: Silvercup Studios. 
Weiner, M. (Writer \& Director). (2015). Person to person [Television series episode]. In W. Bros (Producer), Mad Men. United States: Silvercup Studios.

Who are the women in the labour force? (2010, Mar 25). The Times -

Transcript. Retrieved from http://ezproxy.lib.ryerson.ca/login?url=https://searchproquest-com.ezproxy.lib.ryerson.ca/docview/423020623?accountid=13631

Windels, K. (2008). The construction of gender and creativity in advertising creative departments. Gender in Management: An International Journal, 27(8), 502-519. doi: http://dx.doi.org/10.1108/17542411211279706 
$\underline{\text { Appendix }}$

Dataset 1: Indicates data collected between March 20 and March 29, 2017

Sentiment

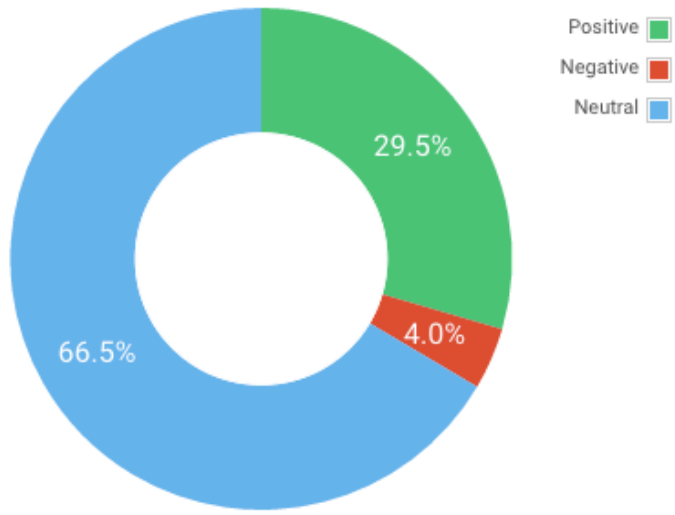

Sentiment Score ?: 88

Figure 1: Sentiment for \#changetheratio Twitter dataset 1

Source: Keyhole: Hashtag \& Keyword Analytics”, 2017

Demographics

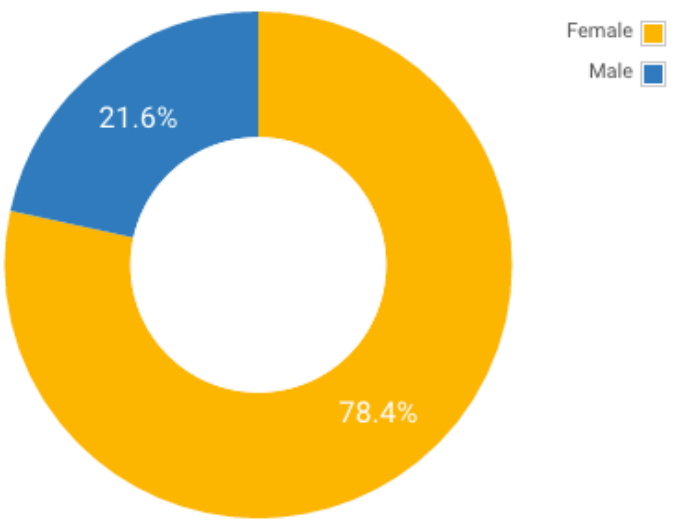

Figure 1a: Demographics for \#changetheratio Twitter dataset 1

Source: Keyhole: Hashtag \& Keyword Analytics", n.d) 


\section{Sentiment 8}

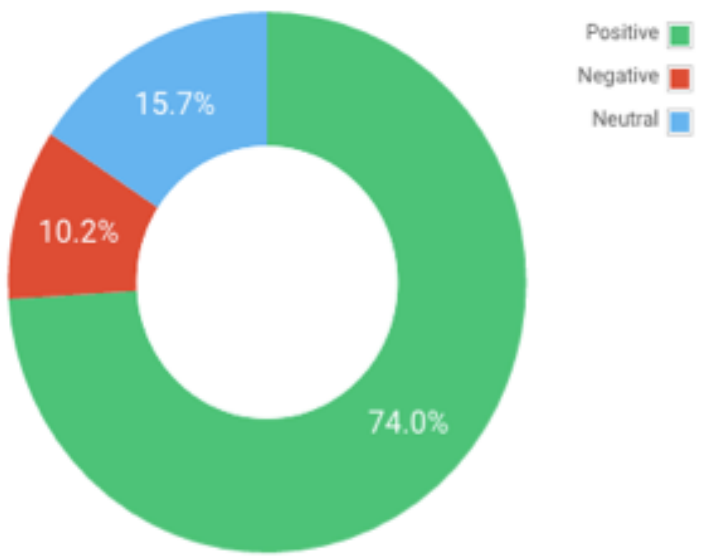

Sentiment Score 8: 87

Figure 2: Sentiment for \#changetheratio Instagram dataset 1.

Source: Keyhole: Hashtag \& Keyword Analytics”, 2017

Demographics

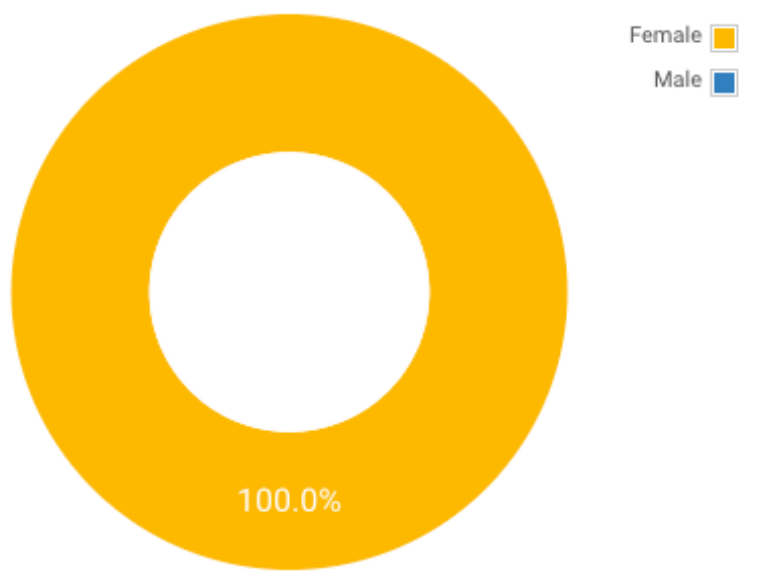

Figure 2a: Demographics for \#changetheratio Instagram dataset 1 
Source: Keyhole: Hashtag \& Keyword Analytics”, 2017

\section{Sentiment 8}

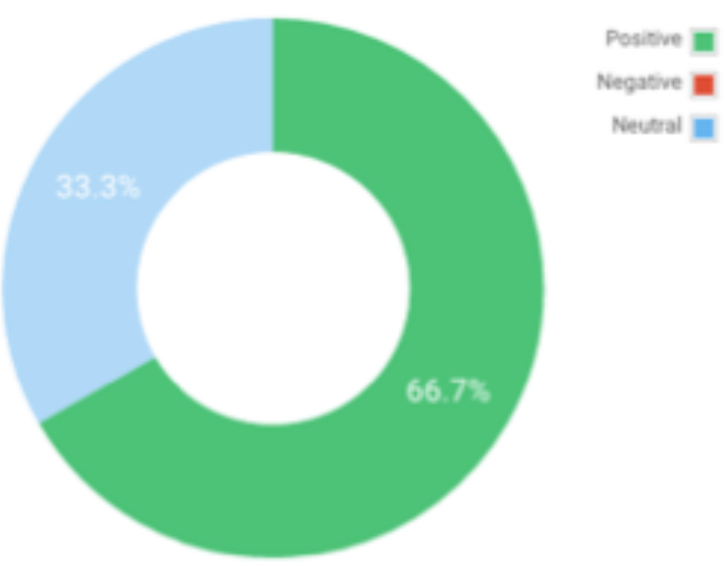

Figure 3: Sentiment for \#3percentconf Twitter dataset 1 Source: Keyhole: Hashtag \& Keyword Analytics”, 2017

\section{Demographics}

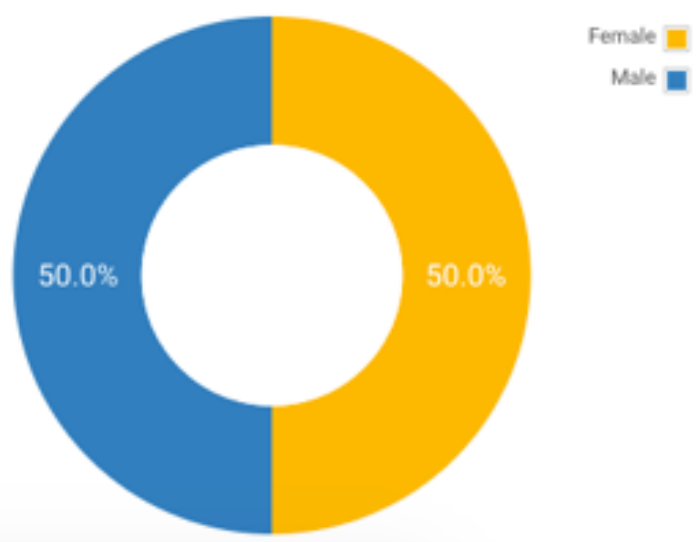

Figure 3a: Demographics for \#3percentconf Twitter dataset 1 Source: Keyhole: Hashtag \& Keyword Analytics”, 2017 
Dataset 2: Indicates data collected between June 17 and June 24, 2017

Sentiment 8

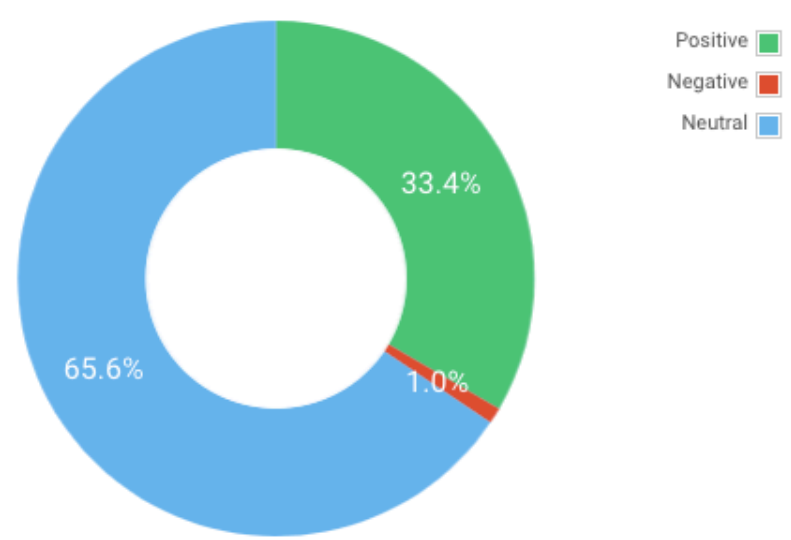

Sentiment Score ?: 97

Figure 4: Sentiment for \#changetheratio on Twitter dataset 2

Source: Keyhole: Hashtag \& Keyword Analytics”, 2017

Demographics

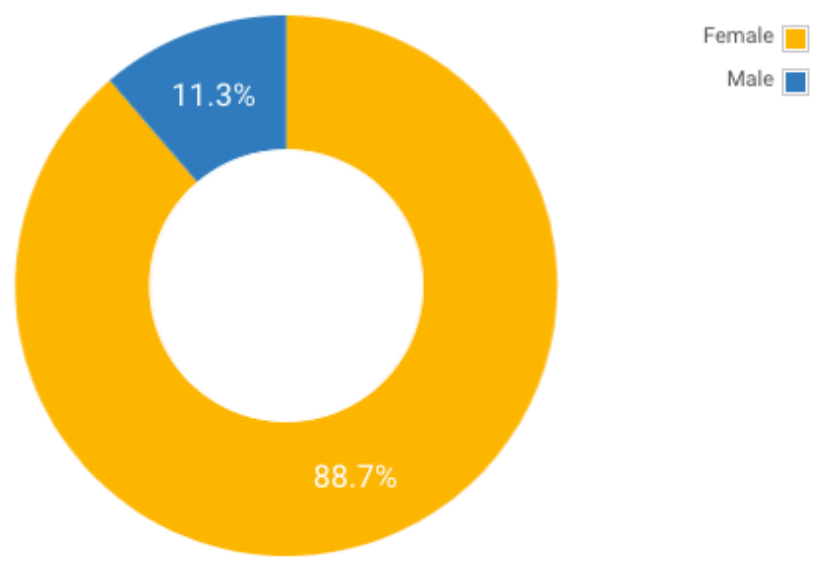

Figure 4a: Demographics for \#changetheratio on Twitter dataset 2

Source: Keyhole: Hashtag \& Keyword Analytics”, 2017 


\section{Sentiment}

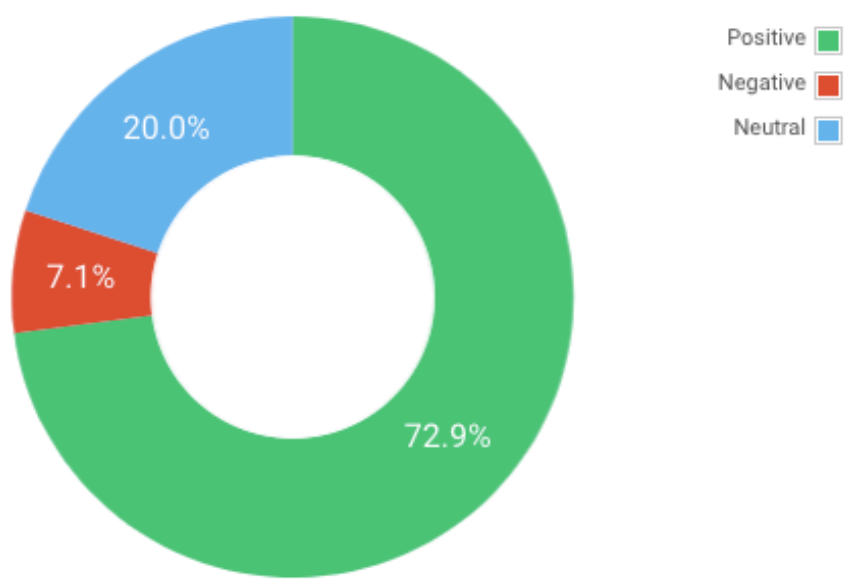

Figure 5: Sentiment for \#changetheratio Instagram dataset 2 Source: Keyhole: Hashtag \& Keyword Analytics”, 2017

\section{Demographics}

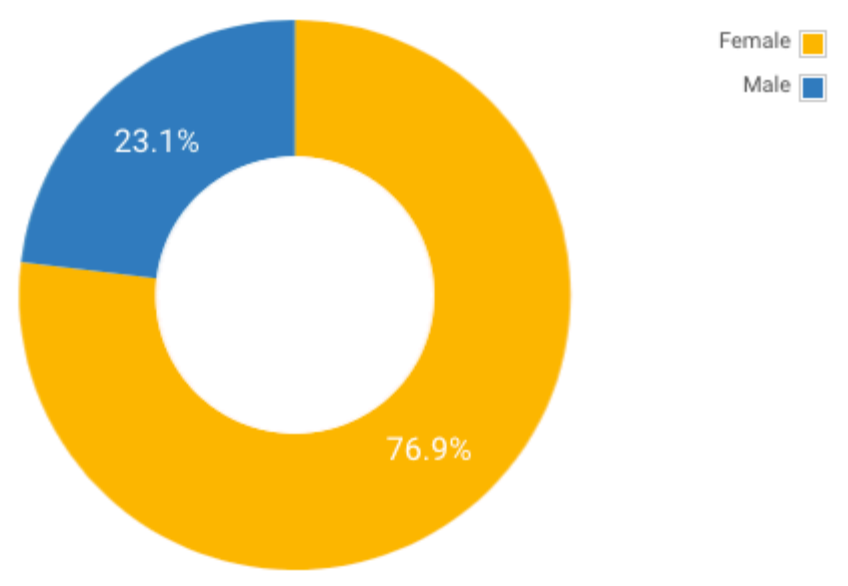

Figure 5a: Demographics for \#changetheratio Instagram dataset 2 Source: Keyhole: Hashtag \& Keyword Analytics”, 2017 


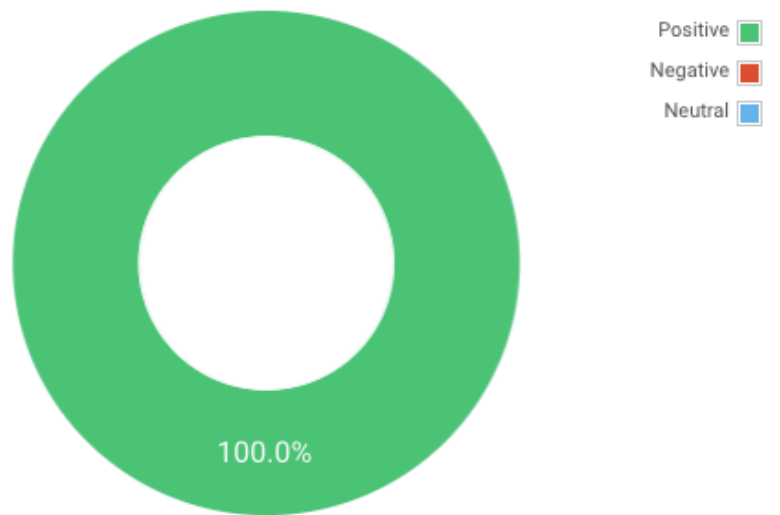

Sentiment Score ?: 100

Figure 6: Sentiment for \#3percentconf Twitter dataset 2 Source: Keyhole: Hashtag \& Keyword Analytics”, 2017

\section{Sentiment}

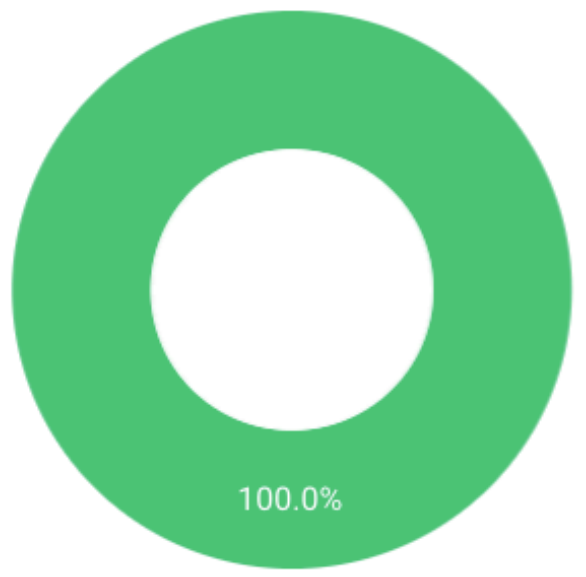

$$
\begin{gathered}
\text { Positive } \square \\
\text { Negative } \square \\
\text { Neutral } \square
\end{gathered}
$$

Figure 7: Sentiment for \#3percentconfo Instagram dataset 2

Source: Keyhole: Hashtag \& Keyword Analytics", 2017 